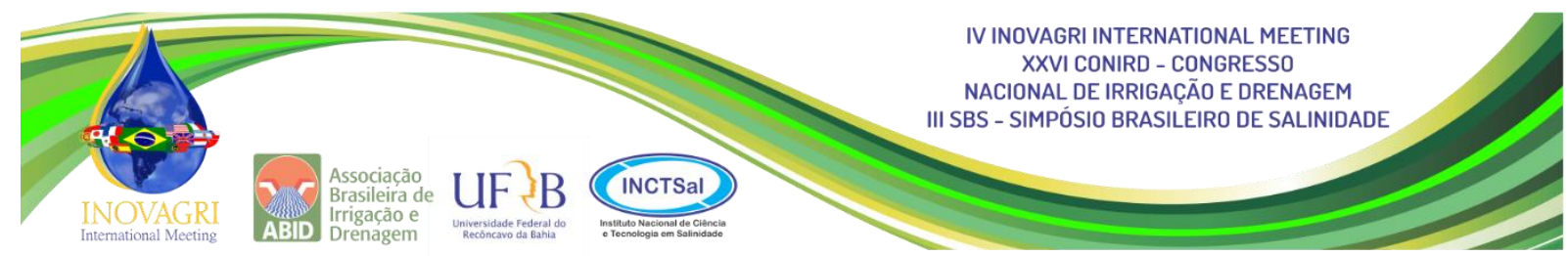

\title{
ADUBAÇÃO ORGÂNICA E FERTIRRIGAÇÃO POTÁSSICA EM VIDEIRA DE VINHO 'SYRAH' I: COMPOSIÇÃO DO MOSTO
}

\author{
A. O. da Silva ${ }^{1}$, D. J. Silva ${ }^{2}$, L. H. Bassoi ${ }^{3}$, J. S. Correia ${ }^{4}$, L. M. Santos ${ }^{5}$.
}

RESUMO: Apesar do aumento da eficiência do uso de fertilizantes o efeito do manejo da adubação potássica nas variedades viníferas utilizadas para a produção de vinhos na região no Submédio do Vale do São Francisco ainda é pouco conhecido. Com o objetivo de avaliar diferentes doses de potássio e adubo orgânico na cultura da videira e sua influência na composição do mosto das uvas, um experimento foi conduzido na Estação Experimental da Embrapa Semiárido em Petrolina-PE. Os tratamentos foram constituídos de cinco doses de potássio $\left(0,20,40,80\right.$ e $\left.160 \mathrm{~kg} \mathrm{ha}^{-1}\right)$ e duas doses de adubo orgânico $\left(0\right.$ e 7,5 dm $\left.\mathrm{dm}^{3}\right)$. O delineamento experimental adotado foi de blocos casualizados com 5 repetições totalizando 50 parcelas experimentais. Para a avaliação do mosto das uvas, 100 bagas foram pesadas e amassadas e no mosto foram determinadas o seu volume; os sólidos solúveis totais, $\mathrm{pH}$ e acidez total por titulação. Os resultados das características químicas do mosto das uvas mostraram que a aplicação de potássio interferiu significativamente $(\mathrm{p}<0,05)$ no $\mathrm{pH}$ do mosto nas diferentes doses de adubo orgânico utilizadas, apresentando um modelo quadrático de regressão.

PALAVRAS-CHAVES: Semiárido, manejo da irrigação, qualidade da uva

\section{ORGANIC FERTILIZER AND POTASSIC FERTIGATION IN WINE VINE 'SYRAH' I: MUST COMPOSITION}

\begin{abstract}
Despite the increase in the efficiency of fertilizer use, the effect of potassic fertilizer management on the grapevines varieties used for the production of wines in the region in the São Francisco Valley is still little known. In order to evaluate different doses of potassium and organic fertilizer in grapevine, an experiment was conducted at the Embrapa Semiarid Experiment Station in Petrolina-PE. The treatments consisted of five doses of potassium $\left(0,20,40,80\right.$ and $\left.160 \mathrm{~kg} \mathrm{ha}^{-1}\right)$ and two doses of organic fertilizer $\left(0\right.$ and $7.5 \mathrm{dm}^{3} \mathrm{ha}^{-}$

\footnotetext{
${ }^{1}$ Professor Dr. Departamento de Engenharia Agrícola da UFC, Av. Mister Hull, 2977, Bloco 804 - Campus do Pici, CEP 60356-001, Fortaleza-CE: alexsandro@ufc.br

${ }^{2}$ Pesquisador Dr. Embrapa Semiárido, Petrolina -PE.

${ }^{3}$ Pesquisador Dr. Embrapa Instrumentação Agrícola, São Carlos -SP

${ }^{4}$ Dr. Engenheiro Agrônomo, Faculdade de Ciências Agronômicas da UNESP, Botucatu-SP.

${ }^{5}$ Bióloga, Acadêmica da Universidade de Pernambuco, Petrolina.
} 
A. O. da Silva et al.

$\left.{ }^{1}\right)$. The experimental design was randomized blocks with 5 replications totaling 50 experimental plots. For the evaluation of the grape must, 100 berries were weighed and kneaded and the volume determined; total soluble solids, $\mathrm{pH}$ and total acidity by titration. The results of the chemical characteristics of the grapes showed that the application of potassium significantly interfered in the $\mathrm{pH}$ of the must in the different doses of organic fertilizer used, presenting a quadratic model of regression.

KEYWORDS: Semiarid region, irrigation management, grape quality

\section{INTRODUÇÃO}

A prática da vitivinicultura tem grande importância comercial e econômica no Submédio do Vale do São Francisco tendo uma grande participação nos 18,8\% do total de uvas produzidas na região nordeste brasileiro, referente a produção nacional (Silva \& Coelho, 2008). O cultivo é realizado em regime de irrigação devido as altas temperaturas encontradas no Semiárido brasileiro sendo os processos fisiológicos acelerados o que possibilita a produção de uvas o ano todo, podendo-se obter até duas safras e meia por ano com produtividade de $30 \mathrm{t} \mathrm{ha}^{-1} \mathrm{ano}^{-1}$.

Apesar da vantagem climática, pouco ainda se sabe quanto ao manejo da adubação, principalmente da utilização de fertilizantes potássicos nas diferentes variedades de viníferas utilizadas para a produção de vinhos na região no Submédio do Vale do São Francisco. Segundo Terra (2003) a adubação da videira é particularmente interessante devido a interferir nos aspectos qualitativos e quantitativos de produção, sendo o potássio $(\mathrm{K})$ o elemento utilizado em maior quantidade, exercendo papel fundamental na fisiologia da planta (Swanton \& Kliewer, 1989), na regulação do balanço iônico celular (Freeman \& Kliewer, 1983), fluxo dos vasos lenhosos e liberianos (Cuéllar et al., 2010), na transpiração (Kodur et al. 2010) e na síntese de macromoléculas como proteínas e amido. Nas uvas, diversos trabalhos (Delgado et al. 2004, Morris et al. 1987, Dundon et al. 1984) mostram que o K influencia de maneira significativa no $\mathrm{pH}$ e na acidez titúlavel do mosto das uvas.

Diante da grande necessidade do uso da irrigação para a prática agrícola no Semiárido brasileiro, a fertirrigação entra como opção para aumentar a eficiência do manejo da adubação na cultura da videira, segundo Silva \& Monteiro, (2009) o manejo da fertirrigação deve ser realizado de acordo com as características do fertilizante, condições climáticas, característica do solo e demanda da cultura, fornecendo a água e nutrientes necessários para o desenvolvimento da videira. Na fertirrigação as fontes de fertilizantes potássicos de maior 
utilização são o cloreto de potássio devido ao seu baixo custo, nitrato de potássio e sulfato de potássio e o sistema de irrigação adotado é o gotejamento.

Este trabalho tem como objetivo avaliar o efeito de diferentes doses de potássio e adubação orgânica nas características do mosto e dos compostos fenólicos das uvas em videiras cv. 'syrah' no Semiárido pernambucano.

\section{MATERIAIS E MÉTODOS}

O experimento foi conduzido na Estação Experimental da Embrapa Semiárido localizada no perímetro irrigado do distrito de Bebedouro em Petrolina-PE (latitude 9॰ 8' 8,9" S, longitude $40^{\circ} 18^{\prime} 33,6^{\prime \prime}$, altitude 373 m). A videira (Vitis vinifera L.) cultivar Syrah foi enxertada sobre o porta enxerto Paulsen 1103, através de estaquia em abril de 2009, com o espaçamento de $1 \mathrm{~m}$ entre plantas e $3 \mathrm{~m}$ entre fileiras com condução em espaldeira, irrigadas por um sistema de irrigação por gotejamento possuindo uma vazão de $2,5 \mathrm{~L} \mathrm{~h}^{-1}$ por emissor, cada planta eram irrigadas por dois emissores espaçados em $0,5 \mathrm{~m}$.

Os tratamentos foram constituídos de cinco doses de potássio $\left(0,20,40,80\right.$ e $160 \mathrm{~kg} \mathrm{ha}^{-}$ $\left.{ }^{1}\right)$ e duas doses de adubo orgânico $\left(0\right.$ e $\left.7,5 \mathrm{dm}^{3} \mathrm{ha}^{-1}\right)$. Estes tratamentos estão dispostos em parcelas subdivididas. $\mathrm{O}$ adubo orgânico constituiu as parcelas e as doses de potássio as subparcelas. A unidade experimental (UE) foi constituída de 16 plantas, utilizando-se 8 plantas úteis por parcela para análises. O delineamento experimental adotado foi de blocos casualizados com 5 repetições, formando um fatorial de $2 \times 5 \times 5$. A adubação orgânica constituída por esterco de caprino (Tabela 1) foi feita previamente antes das podas de produção realizadas nos dias 29/04/2013. A adubação potássica foi realizada no período de 10 semanas (1 semana após as podas de produção) via fertirrigação com o auxílio de bomba injetora com vazão de $360 \mathrm{~L} \mathrm{~h}^{-1}$, os adubos potássicos utilizados foram o cloreto de potássio $\left(\mathrm{K}_{2} \mathrm{O}=60 \%\right)$, nitrato de potássio $\left(\mathrm{K}_{2} \mathrm{O}=45 \%\right)$ e sulfato de potássio $\left(\mathrm{K}_{2} \mathrm{O}=50 \%\right)$.

O solo da área foi classificado como Argissolo Vermelho Amarelo Eutrófico Latossólico (Embrapa, 1999), textura média, apresentando a seguinte composição (Embrapa, 1997): areia $81 \mathrm{~g} \mathrm{~kg}^{-1}$, silte $13 \mathrm{~g} \mathrm{~kg}^{-1}$ e argila $6 \mathrm{~g} \mathrm{~kg}^{-1}$, caracterizado como solo arenoso. A composição química do solo encontra-se na Tabela 2.

Durante todos os ciclos de produção dados climáticos de temperatura (máxima e mínima), umidade relativa do ar, precipitação, evapotranspiração de referência pelo método de Penman-Monteith (Allen et al. 1998) e insolação solar (horas), foram monitoradas (Tabela 3), para o manejo da irrigação e observação do comportamento das plantas através de uma estação 
A. O. da Silva et al.

meteorológica a 60m de distância do experimento. Os valores de Kc adotados para o manejo da irrigação foram obtidos por Bassoi et al. (2007) na mesma área através da utilização de lísimetros de pesagem.

A colheita foi realizada aos 116 dias após a poda de produção (dapp) no dia 23/08/2013. As uvas foram levadas em contentores para o Laboratório de Enologia da Embrapa Semiárido onde foram separadas em duas partes, armazenadas e refrigeradas. Posteriormente, parte das bagas de uva (100 bagas) foram pesadas e amassadas e no mosto foram determinadas o seu volume $(\mathrm{mL})$; os sólidos solúveis totais $\left({ }^{\circ} \mathrm{Brix}\right)$ com refratômetro digital portátil, $\mathrm{pH}$ com phmetro digital de bancada e a acidez total por titulação com $\mathrm{NaOH} 0,1 \mathrm{~N}$, usando o azul de bromotimol como indicador (Brunetto et al., 2007).

Os resultados obtidos foram submetidos à analise de variância e quando os efeitos foram significativos, foram ajustados equações de regressão, testando-se os modelos linear e polinomial quadrático pelo teste $\mathrm{F}$, escolhendo-se aqueles com significância menor que $5 \%$ $(\mathrm{P}<0,05)$. Todas as análises estatísticas foram realizadas pelo software estatistico Sisvar (Ferreira, 2008).

\section{RESULTADOS E DISCUSSÃO}

Os resultados das características químicas do mosto das uvas (Tabela 2) mostraram que a aplicação de potássio interferiu significativamente no $\mathrm{pH}$ do mosto nas diferentes doses de adubo orgânico utilizadas, apresentando um modelo quadrático de regressão, tais efeitos também foram relatados por Brunetto et al. (2007) em estudos de viníferas Cabernet Sauvignon submetidas a diferentes doses de nitrogênio. A acidez titúlavel apresentou efeito significativo para a dose de adubo orgânico de 7,5 $\mathrm{dm}^{-3} \mathrm{ha}^{-1}$ com um modelo linear de regressão, havendo um aumento de 0,009 meq $\mathrm{L}^{-1}$ de acordo com o aumento unitário da dose de potássio aplicada $\left(\mathrm{kg} \mathrm{ha}^{-1}\right)$. Os solídos solúveis totais (brix), peso de 100 bagas e o volume do mosto não apresentaram efeito significativo para os fatores avaliados no experimento.

Morris et al. (1987) em estudos sobre o excesso de potássio e sua influência na produção e qualidade de uvas de vinho em cinco cultivares (Gewurztraminer, Cabernet Sauvignon, Seyval, de Chaunac e Cynthiana) de videiras observaram diferenças significativas no $\mathrm{pH}$ das uvas da cultivar Cabernet Sauvignon nos diferentes tratamentos envolvendo o fator K, enquanto o sólido solúveis totais não apresentaram diferenças relacionadas ao envolvimento da adubação potássica. Estes resultados também foram observados por Dundon et al. (1984) em estudos sobre o efeito de diferentes fertilizantes potássicos na composição do mosto de videiras 'syrah', 
não observaram diferenças significativas em relação as fontes de K utilizadas, porém houve um aumento do brix nas uvas de acordo com a época de produção (ciclos produtivos posteriores).

\section{CONCLUSÕES}

A aplicação crescente de potássio nas diferentes doses de adubo orgânico aplicadas afetou apenas o pH e a acidez títulavel na composição do mosto das uvas. Não havendo alterações no teor de sólidos solúveis totais, volume do mosto e peso das bagas.

\section{REFERÊNCIAS}

ALLEN, R.G.; PEREIRA, L.S.; PAES, D.; SMITH, M. Crop evapotranspiration: guidelines for computing crop water requirements. Roma: FAO, 1998, 328p. (Irrigation and Drainage Paper, 56).

BASSOI, L. H.; DANTAS, B. F.; LIMA FILHO, J. M. P.; LIMA, M. A. C.; LEÃO, P. C.S.; SILVA, D. J.; MAIA, J. T. L.; SOUZA, C. R. Preliminary results of a long -term experiment about RDI and PRD irrigation strategies in winegrapes in São Francisco Valley, Brazil. Acta Hort. V.754, p.275-282, 2007.

BRUNETTO, G.; CERETTA, C. A.; KAMINSKI, J.; MELO, G. W. B.; LOURENZI, C. R.; FURLANETTO, V.; MORAES, A. Aplicação de nitrogênio em videiras na Campanha Gaúcha: produtividade e características químicas do mosto da uva. Ciência Rural, v. 37, n. 2, p. 389393, 2007.

CUÉLlAR, T.; PASCAUD, F.; VERDEIL, J. L.; TORREGROSA, L.; BLONDOM, A. F. A. B.; THIBAUD, J. B.; SENTENAC, H.; GAILLARD, I. A grapevine shaker inward K+ channel activaded by the calcineurin B-like calcium sensor 1-protein kinase CIPK23 network is expressed in grapes berries under drought stress conditions. The Plant Journal, v.61, p.58-59, 2010.

DELGADO, R.; MARTÍN, P.; ALAMO, M.; GONZÁLEZ, M. R. Changes in the phenolic composition of grape berries during ripering in relation vineyard nitrogen and potassium fertilisation. Journal of the Science of Food and Agriculture, v.84, p.623-630, 2004.

DUNDON, C. G.; SMART, R. E.; MCCARTHY, M. G. The effect of potassium fertilizer on must and wine potassium levels of shiraz grapevines. American Journal Enology and Vitiviniculture, v. 35, n. 4, p.200-205, 1984. 
EMBRAPA. Empresa Brasileira de Pesquisa Agropecuária. Centro Nacional de Pesquisas de Solos. Sistema Brasileiro de classificação de solos. Rio de Janeiro: Embrapa Solos. 1999. 412p. EMBRAPA - Empresa Brasileira de Pesquisa Agropecuária. Serviço nacional de levantamento e conservação do solo. Manual de Métodos de análises de solo. 2. Ed. Rio Janeiro: EMBRAPA, 1997. 212p.

FERREIRA, D. F. Sisvar: Um programa para análises e ensino de estatística. Revista Symposium, v.6, p.36-41, 2008.

FREEMAN, B. M.; KLIEWER, W. M. Effect of irrigation, crop level and potassium fertilization on Carignane vines. II. Grapes and wine quality. American Journal Enology and Vitiviniculture, v.34, n.3, 197-207, 1983.

KODUR, S.; TISDALL, J. M.; TANG, C.; WALKER, R. R. Accumulation of potassium in grapevine rootstocks (vitis) as affected by dry matter partitioning, root traits and transpiration. Australian Journal of Grape and Wine Research, v.16, p.273-282, 2010.

MORRIS, J. R.; SIMIS, C. A.; STRIEGLER, R. K.; CACKLER, S.D.; DONLEY, R. A. Effects of cultivar, maturity, cluster thining and expressing potassium fertilization on yield and quality of Arkansas wine grapes. American Journal Enology and Vitiviniculture, v.38, n. 4, 260264, 1987.

SILVA, P. C. G.; COELHO, R. C. Cultivo da videira: caracterização social e econômica da cultura da videira. 2aed. Petrolina: Embrapa semiárido, 2010, 3p. (comunicado técnico).

SWANTON, B. A.; KLIEWER, W. M. Characterizing potassium uptake and accumulation by grape rootstocks: The xylem potassium approximation. Journal of Plant Nutrition, v.12, n.2, p.145-158, 1989.

TERRA, M. M. Nutrição, calagem e adubação. In: POMMER, C. V. (Ed.). Uva: tecnologia de produção, pós-colheita, mercado. Porto Alegre: Cinco Continentes, 2003. p. 405-476. 
Tabela 1. Composição química do esterco utilizado

\begin{tabular}{|c|c|c|c|c|c|c|c|c|c|c|c|c|c|}
\hline $\mathrm{pH}$ & $\mathrm{CE}$ & $\mathrm{N}$ & $\mathrm{P}$ & K & $\mathrm{Ca}$ & $\mathrm{Mg}$ & $\mathrm{S}$ & \multirow[t]{2}{*}{ B } & $\mathrm{Cu}$ & $\mathrm{Fe}$ & $\mathrm{Mn}$ & $\mathrm{Zn}$ & \multirow[t]{2}{*}{$\mathrm{Na}$} \\
\hline & $\mathrm{dS} \mathrm{m}^{-1}$ & & ----- & 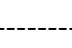 & $\mathrm{g} \mathrm{kg}^{-1}$ & 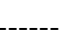 & 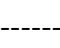 & & \multicolumn{4}{|c|}{ 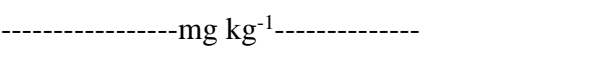 } & \\
\hline 5,1 & 0,32 & 3,5 & 2,2 & 13,8 & 13,1 & 4,7 & 2,3 & 37,3 & 21,2 & 4495,0 & 338,7 & 55,2 & 1482,7 \\
\hline
\end{tabular}

Tabela 2. Propriedades químicas do solo

\begin{tabular}{|c|c|c|c|c|c|c|c|c|c|c|}
\hline $\mathrm{pH}$ & CE & M.O & $\mathrm{P}$ & K & $\mathrm{Ca}$ & $\mathrm{Mg}$ & $\mathrm{H}+\mathrm{Al}$ & $\mathrm{Na}$ & CTC & V \\
\hline $\mathrm{CaCl}_{2}$ & $\mathrm{dSm}^{-1}$ & $\mathrm{~g} \mathrm{dm}^{-3}$ & $\mathrm{mg} \mathrm{dm}^{-3}$ & & $---\cdot$ & --1 & $\mathrm{dm}^{-3}-$ & ------ & & $(\%)$ \\
\hline 6,7 & 0,46 & 10,4 & 88,8 & 0,38 & 2,54 & 0,98 & 0,05 & 0,03 & 4,92 & 81 \\
\hline
\end{tabular}

CE - Condutividade elétrica, M.O - Matéria orgânica, K - potássio, Ca - Cálcio, Mg - magnésio, Na- sódio, H+Al - acidez potencial, CTC - complexo de troca catiônica, V - saturação por bases.

Tabela 3. Dados climáticos ocorridos durante o experimento.

\begin{tabular}{ccccc}
\hline \multirow{2}{*}{ Meses } & \multicolumn{3}{c}{ Temperatura } & Umidade \\
\cline { 2 - 4 } & T. Mín & T. Máx & T. Med & UR. Med \\
\cline { 2 - 4 } & \multicolumn{2}{c}{------------ ${ }^{\circ}$ C--------------- } & \% \\
\hline Abr - 2013 & 23,6 & 33,6 & 27,8 & 60,0 \\
Mai - 2013 & 21,9 & 32,5 & 26,5 & 58,3 \\
Jun - 2013 & 20,8 & 32,0 & 25,8 & 59,0 \\
Jul - 2013 & 19,6 & 31,2 & 24,7 & 54,0 \\
Ago- 2013 & 19,8 & 31,6 & 25,2 & Insolação \\
\hline
\end{tabular}

Tabela 4. Características químicas e produtivas das uvas da variedade 'syrah'submetida a diferentes doses de potássio e adubo orgânico

\begin{tabular}{|c|c|c|c|c|c|c|c|}
\hline \multirow{2}{*}{$\begin{array}{c}\text { A.O } \\
\left(\mathrm{dm}^{3} \mathrm{ha}^{-1}\right)\end{array}$} & \multicolumn{5}{|c|}{ Dose de $\mathrm{K}_{2} \mathrm{O}\left(\mathrm{kg} \mathrm{ha}^{-1}\right)$} & \multirow{2}{*}{ Equação } & \multirow{2}{*}{$\mathrm{R}^{2}$} \\
\hline & 0 & 20 & 40 & 80 & 160 & & \\
\hline \multicolumn{8}{|c|}{ 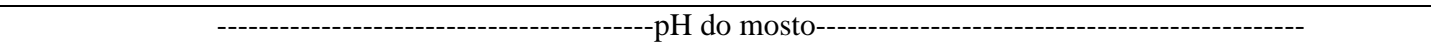 } \\
\hline 0 & 3,64 & 3,68 & 3,84 & 3,69 & 3,67 & $y=0,00006 x^{2}+0,0049 x+3,662$ & 0,23 \\
\hline 7,5 & 3,65 & 3,67 & 3,77 & 3,80 & 3,80 & $y=0,00006 x^{2}+0,0065 x+3,637$ & 0,65 \\
\hline \multicolumn{8}{|c|}{-------------------------------------Acidez total $\left(\mathrm{meq} \mathrm{L}^{-1}\right.$ )------------------------------ } \\
\hline 0 & 7,43 & 7,43 & 6,98 & 7,99 & 7,61 & Ns & - \\
\hline 7,5 & 7,24 & 7,16 & 7,31 & 7,39 & 7,91 & $y=0,009 x+7,132$ & 0,48 \\
\hline \multicolumn{8}{|c|}{ 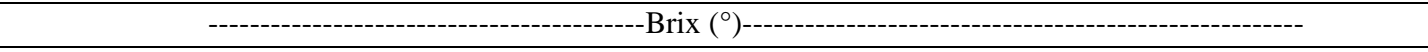 } \\
\hline 0 & 22,9 & 22,5 & 23,0 & 22,3 & 22,2 & Ns & - \\
\hline 7,5 & 22,3 & 23,2 & 22,6 & 22,8 & 22,4 & Ns & - \\
\hline \multicolumn{8}{|c|}{-------------------------------------'Peso de 100 bagas (g)-------------------------------- } \\
\hline 0 & 171 & 167 & 170 & 168 & 160 & Ns & - \\
\hline 7,5 & 160 & 164 & 170 & 163 & 160 & Ns & - \\
\hline \multicolumn{8}{|c|}{ 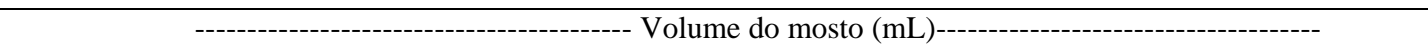 } \\
\hline 0 & 83,3 & 84,8 & 88,9 & 88,5 & 82,5 & $\mathrm{Ns}$ & - \\
\hline 7,5 & 84,0 & 84,0 & 86,0 & 81,3 & 84,9 & Ns & - \\
\hline
\end{tabular}

Ns - Não significativo 